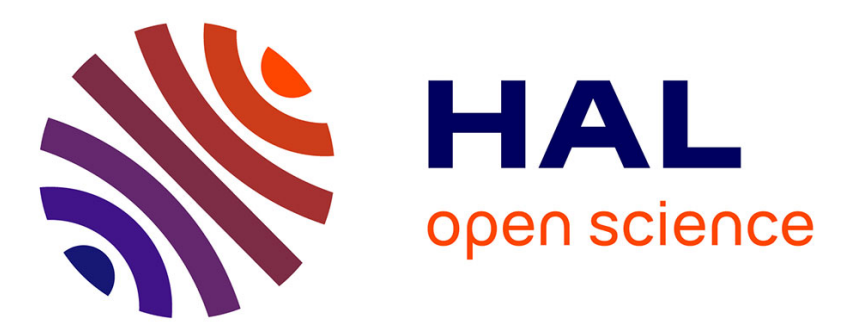

\title{
Multi-scale analysis of short glass fiber-reinforced polypropylene under monotonic and fatigue loading
}

Mohamed A. Imaddahen, Mohammadali Shirinbayan, Houssem Ayari, Mathieu Foucard, Abbas Tcharkhtchi, Joseph Fitoussi

\section{- To cite this version:}

Mohamed A. Imaddahen, Mohammadali Shirinbayan, Houssem Ayari, Mathieu Foucard, Abbas Tcharkhtchi, et al.. Multi-scale analysis of short glass fiber-reinforced polypropylene under monotonic and fatigue loading. Polymer Composites, 2020, 41 (11), pp.4649-4662. 10.1002/pc.25740 . hal-03166953

\section{HAL Id: hal-03166953 \\ https://hal.science/hal-03166953}

Submitted on 11 Mar 2021

HAL is a multi-disciplinary open access archive for the deposit and dissemination of scientific research documents, whether they are published or not. The documents may come from teaching and research institutions in France or abroad, or from public or private research centers.
L'archive ouverte pluridisciplinaire HAL, est destinée au dépôt et à la diffusion de documents scientifiques de niveau recherche, publiés ou non, émanant des établissements d'enseignement et de recherche français ou étrangers, des laboratoires publics ou privés. 


\title{
Multi-scale analysis of short glass fiber-reinforced polypropylene under monotonic and fatigue loading
}

\author{
Mohamed A. Imaddahen ${ }^{1,2}$ () ｜ Mohammadali Shirinbayan ${ }^{1}$ (i) | Houssem Ayari ${ }^{1}$ | \\ Mathieu Foucard $^{2}$ | Abbas Tcharkhtchi ${ }^{1}$ | Joseph Fitoussi ${ }^{1}$
}

${ }^{1}$ PIMM, Arts et Metiers Institute of Technology, CNRS, Cnam, HESAM University, 151 boulevard de l'Hopital, Paris, 75013, France

${ }^{2}$ Flex-N-Gate Exteriors Europe, Audincourt, France

Correspondence

Mohamed A. Imaddahen, Arts et Metiers Institute of Technology, CNRS, Cnam, HESAM University, PIMM-UMR CNRS 8006, 151 Boulevard de l'Hôpital, 75013 Paris, France.

Email: mohamed-amine.imaddahen@ ensam.eu

\section{Funding information}

Association Nationale de la Recherche et de la Technologie, Grant/Award Number: scholarship; FLEX-N-GATE Exteriors Europe, Grant/Award Number: scholarship + Materials

\begin{abstract}
Short fiber-reinforced polypropylene is largely used in the automotive industry. Fatigue failure is one of the most failure modes observed in this class of materials. In order to better understand the damage mechanisms and plasticity evolution, this article provides an overall experimental investigation of the mechanical properties of a PPGF40 composite (polypropylene matrix reinforced by a $40 \%$ weight content of short glass fibers) including monotonic and cyclic loading. The effect of various parameters such as the loading direction, the strain rate, the temperature, and the fatigue are analyzed. The evolutions of the loss of stiffness and plastic strain during monotonic and fatigue tests are analyzed. Self-heating during cyclic loading is also studied. Moreover, the coupling effect of damage and plasticity is analyzed by plotting the evolution of the relative loss of stiffness vs the plastic strain increment for monotonic and cyclic loadings. For quasi-static loading, the results emphasize an intrinsic curve independent of the loading direction. Moreover, a sharp increase in the damage and plasticity levels due to the local effect occurring during cyclic loading is observed and correlated to SEM fracture surface analysis.
\end{abstract}

\section{K E Y W O R D S}

fatigue analysis, fracture, mechanical properties, polypropylene, thermoplastics

\section{1 | INTRODUCTION}

Short fiber-reinforced thermoplastics (SFRT) are widely used in the automotive industry. Their high strength-toweight ratio, reprocessing quality, low-manufacturing price, and ability to be shaped using a conventional molding process such as injection make them great materials for automotive components with complex geometry and a high-volume production rate. ${ }^{[1,2]}$

Among them, short fiber-reinforced polypropylene is largely used for the manufacturing of automotive exterior parts such as the bumpers and the hatch due to its low density, allowing high-fiber content filling and low-water absorption in comparison with polyamide. ${ }^{[3]}$ For such a use, glass fiber-reinforced polypropylene must exhibit great structural durability especially against mechanical and thermal fatigue loading. For example, tailgates (cars back doors), are stressed in fatigue with opening and closing cycles of up to 70000 cycles.

It is commonly known that the damage evolution for SFRT during fatigue occurs in three stages ${ }^{[4-6]}$ : the first stage is described by a high reduction in stiffness due to damage mechanisms such as fiber/matrix debonding and matrix cracking. The second stage corresponds to the coalescence and propagation of microcracks. A gradual stiffness decrease is observed in this stage. The last stage is 
characterized by a drastic decline in stiffness due to rapid crack propagation leading to failure. The Analysis of the stiffness reduction during loading-unloading monotonic tests is used by several authors ${ }^{[7-9]}$ to evaluate the macroscopic damage evolutions of SFRC. During the fatigue test, the dynamic modulus (slope of the stress-strain hysteresis) is commonly used as a damage indicator. ${ }^{[4,10-12]}$ Arif et $\mathrm{al}^{[13]}$ applied the dynamic modulus to evaluate the damage evolution during fatigue loading. They concluded that the latter might overpredict the damage evolution for high amplitude due to the high-viscous effect of the composite.

Bellenger et $\mathrm{al}^{[14]}$ studied the thermal and mechanical fatigue of a PA66/glass fiber composite material. They focused on analyzing the effect of the physical state of the matrix on the fatigue behavior and the failure surfaces. They showed that the fatigue behavior of thermoplastic composites could be obtained by inducing the thermal and mechanical fatigue. The induced temperature was not only caused by the damping induced by crack initiation but also by the change in the physical state of the matrix. There was a fast increase of the loss modulus $\mathrm{E}^{\prime \prime}$ at the glass transition temperature hence the increase in the dissipated energy at each loading cycle. They concluded that the damage is initiated at fiber ends close to sample edges where the stress concentration was the highest.

In another study, ${ }^{[15,16]}$ the results showed that the thermal fatigue had a very significant role in rising temperature and decreasing fatigue lifetime. Consequently, it is necessary to know the conditions at which thermal fatigue happens.

Zuo et $\mathrm{al}^{[12]}$ studied the multiscale analysis of the effect of loading conditions on the monotonic and fatigue behavior of a glass fiber-reinforced polyphenylene sulfide composite. They concluded that the increasing frequency would lead to lower fatigue lifetime and more generalized plasticity. They demonstrated that fiber orientation in the loading direction would improve both the monotonic and fatigue strength.

Shirinbayan et $\mathrm{al}^{[17,18]}$ studied the coupled effect of the loading frequency and amplitude on the fatigue behavior of an advanced sheet molding compound (ASMC). They also studied the isodamage evolution curves obtained from postfatigue dynamic tests to those which could be obtained in monotonic dynamic traction. The comparison was done on equivalent $\mathrm{E}$ damage states corresponding to different values of the lifetime fraction, $\mathrm{N} / \mathrm{Nr}$. They concluded that the elastic modulus remained insensitive to the strain rate for predamaged A-SMC composites. The fatigue predamaged samples showed a remaining monotonic mechanical potential always lower than the virgin samples.
Moreover, polymeric composites are known to exhibit strong time and temperature dependence. ${ }^{[19-25]}$ For polymers, it is known that Young's modulus and the maximum stress increase with the strain rate and decrease with the temperature. For a glass fibers reinforced polypropylene based copolymer, ${ }^{[26]}$ Fitoussi et al emphasized a strong increase in all the mechanical properties (including ultimate strain) with the strain rate. These authors introduced the concept of visco-damage occurring at the local scale due to both plastic deformation of the matrix and the strain rate dependence of the fiber matrix interfacial strength. For moderate to high-strain rates, Jendli et $\mathrm{al}^{[20,27]}$ also emphasized this effect for a short fiberreinforced thermoset.

The work of Horst and Spoormaker ${ }^{[28,29]}$ on the damage mechanisms of short glass fiber polyamide 6.6 in quasi-static and fatigue allowed proposing a scenario of damage in fatigue similar to that of Sato, ${ }^{[30,31]}$ mainly based on the creation of a vacuum at the matrix fiber interface. Since then, this scenario has been widely validated in the literature ${ }^{[32,33]}$ and has affirmed its independence from many parameters, including the type of loading and the temperature. For both researchers, the difference between each loading would lead to the level of the kinetics of the damage propagation.

A good understanding of the damage phenomenon at the macroscopic and the microscopic scales is therefore necessary to better size this type of structure and to propose criteria and models capable of predicting their mechanical response. On the other hand, the bibliographic research has not provided many studies concerning the damage and plasticity evolution during the fatigue of these type of materials. The investigation of the monotonic and fatigue properties of these composites including damage and plasticity evolution as well as coupling, is the main objective of this study.

In this article, we propose an overall experimental characterization of the mechanical properties of short glass fibers reinforced polypropylene at different fiber orientations $\left(0^{\circ}, 45^{\circ}\right.$, and $90^{\circ}$ vs injection molding direction). Due to the different application conditions, monotonic tensile tests at different strain rates $(0.0001$, 0.04 , and $\left.0.25 \mathrm{~s}^{-1}\right)$ and temperatures $\left(-30^{\circ} \mathrm{C}, 23^{\circ} \mathrm{C}\right.$, and $80^{\circ} \mathrm{C}$ ) are performed. Loading-unloading tests are performed at room temperature at a quasi-static strain rate $\left(4.10^{-4} \mathrm{~s}^{-1}\right)$ to analyze the macroscopic damage evaluation.

The progressive loss of stiffness and the macroscopic residual strain increase are used to characterize damage and apparent plasticity evolution. Tensile-tensile fatigue tests are performed at frequencies of 1 and $10 \mathrm{~Hz}$ and a stress ratio of $R=0.1$. Damage analysis during fatigue is proposed by mean of dynamic modulus, plastic strain, 
and self-heating evolution. Finally, the scanning electronic microscope (SEM) observation of fracture surfaces at quasi-static and fatigue loading is performed to understand the failure mode and the damage mechanisms occurring for both loading conditions.

\section{2 | MATERIAL AND EXPERIMENTAL PROCEDURE}

\section{1 | Material description}

The studied material is a $40 \%$ (weight content) short glass fibers reinforced polypropylene provided by FLEXNGATE (PPGF40). The material is obtained by the compounding polypropylene pellets and short glass fibers. The material is then injected to obtain $400 * 320 *$ $3 \mathrm{~mm}^{3}$ rectangular plate.

\section{2 | Microstructure characterization methods}

\subsection{1 | Microscopic observations}

Microscopic observations and image analysis, using SEM (HITACHI 4800 SEM) are performed to qualitatively investigate the material microstructure, especially the fiber orientation. The SEM observation of the fracture surfaces of the specimen after tensile and fatigue tests are performed and a comparison of the damage mechanisms and the fracture mode is then proposed.

\subsection{2 | Ultrasonic measurement}

The ultrasonic wave propagation measurement is used to characterize the orientation and spatial distribution in a short glass reinforced composite plate. Indeed, several authors ${ }^{[34,35]}$ used an innovative ultrasonic immersion method to characterize the fiber orientation of short fiber-reinforced polymers. Here, the same characterization method is used. The sample is placed between two probes to create an ultrasonic wave propagating in the material through the water. An angle of $45^{\circ}$ is respected between the sample and the incident ultrasonic wave in order to create shear waves propagating in the plane defined by the incident ultrasonic direction and the normal vector to the sample. The latter is then rotated from $0^{\circ}$ to $360^{\circ}$ by a step of $30^{\circ}$ around its normal vector. This rotation allows the shear wave to propagate through different material planes. Knowing the distance between the two probes, the sample thickness and the time taken by the wave to propagate, between the two probes, as well as the velocity of the ultrasonic shear wave in the material are then calculated. The variation in the ultrasonic velocity allows a direct quantification of the amount of fibers orientated in the different planes of propagation. Indeed, the presence of fibers in a specific propagation plane increases the ultrasonic velocity.

\section{Experimental procedure}

We start by immersing two identical probes in a tank filled with water: a first transmitter marked (E.) and a second receiver marked (R). The two probes are positioned opposite each other at a well-known distance (d). The first step is to measure the speed of wave propagation in the liquid alone, using an oscilloscope, we determine the flight time $T_{0}$ and knowing the distance we deduce the speed $\mathrm{V}_{0}$ : Figure 1

$$
V_{o}=\frac{d}{t_{o}}
$$

In a second step, we have on the ultrasonic path, the element of our material by which we want to know the main fiber orientation (Figure 2). This element is arranged perpendicular to the ultrasonic wave. This generates longitudinal waves $\mathrm{V}_{\mathrm{OL}}$ (compression wave) in the material propagating in the thickness of the material. Thickness " $\mathrm{e}$ " is usually determined using a micrometer. We then measure the new flight time $t_{e}$ (still using an oscilloscope).

The flight time $t_{e}$ is then equal to:

$$
t_{e}=\frac{d-e}{V_{o}}+\frac{e}{V_{e}}
$$

where $\mathrm{V}_{\mathrm{e}}$ is the velocity of the longitudinal waves in the sample. After doing the calculation, we get:

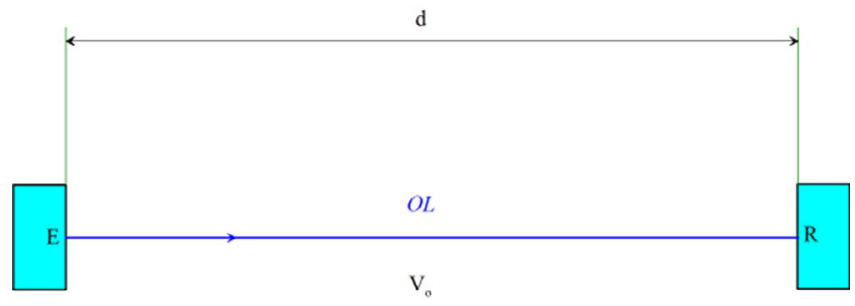

FIG URE 1 Principle of the ultrasonic method: determination of the speed $\mathrm{V}_{0}$ [Color figure can be viewed at wileyonlinelibrary.com] 


$$
V_{e}=\frac{e}{t_{e}-\frac{d-e}{V_{o}}}=V_{O L}
$$

A third step in the ultrasound analysis is to rotate the sample using the device illustrated in Figure 3-a by an angle of incidence (i). This configuration makes it possible to generate transverse waves which will in turn propagate at speed $\mathrm{V}_{\mathrm{OT}}$ through the thickness of the sample in a direction ( $r$ ) governed by the Snell-Descartes law (Figure 3B)

$$
\frac{\sin (\mathrm{i})}{\mathrm{V}_{0}}=\frac{\sin (\mathrm{r})}{\mathrm{V}_{0 \mathrm{~T}}}
$$

On the oscilloscope we read the new flight time $t_{e}$. By taking into account the routes EA and BR, which are made at speed $V_{o}$ and the course $A B$ which takes place at speed $\mathrm{V}_{\mathrm{OT}}$, and considering the Snell-Descartes law, we get:

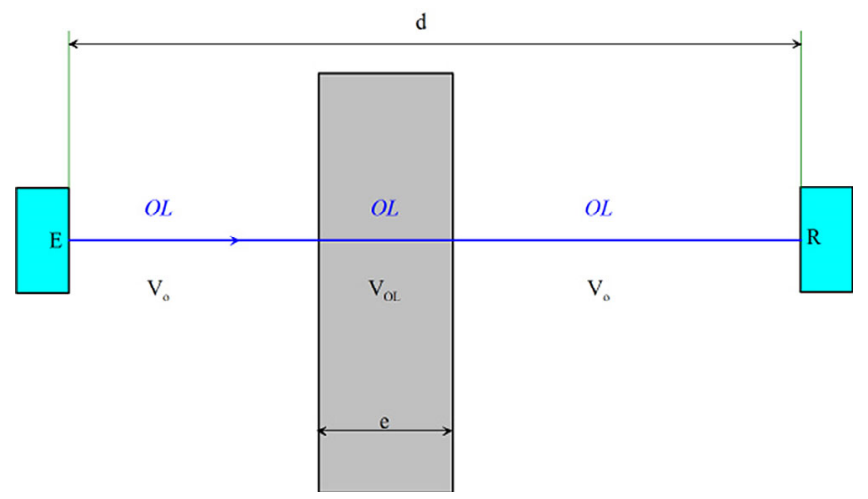

F I G URE 2 Principle of the ultrasonic method: determination of speed $\mathrm{V}_{\mathrm{OL}}$ [Color figure can be viewed at wileyonlinelibrary.com]

$$
V_{O T}=\frac{e V_{o}}{\sqrt{e^{2}+2 e V_{o}\left(t_{e}-t_{o}\right) \cos (i)+V_{o}^{2}\left(t_{e}-t_{o}\right)^{2}}} .
$$

The sample is then rotated from 0 to $360^{\circ}$ by a step of $30^{\circ}$ around its normal vector, the results are represented in Figure 7B.

\subsection{3 | DMTA-analysis}

To measure the main transition temperature, thermomechanical (DMTA) tests have been performed using DMA Q800 instrument, from TA Company. The tests are realized according to the following conditions: dual cantilever configuration; temperature range from $-75^{\circ} \mathrm{C}$ to $125^{\circ} \mathrm{C}$; frequency of 1 and $10 \mathrm{~Hz}$; and temperature rate $2^{\circ} \mathrm{C} / \mathrm{min}$.

\section{3 | Mechanical characterization methods}

\subsection{1 | Monotonic tension behavior}

Monotonic tensile tests until failure are performed using a servo-hydraulic machine MTS 830 according to the ISO 527 standard at crosshead speed variating from 2 to $1200 \mathrm{~mm} / \mathrm{min}$, which correspond to strain rates ranging from $4.10^{-4}$ to $0.25 \mathrm{~s}^{-1}$. The temperature effect is also studied by performing tensile test at a controlled temperature of $85^{\circ} \mathrm{C}$ and $-30^{\circ} \mathrm{C}$ at $4.10^{-4} \mathrm{~s}^{-1}$. In this case, specimens are conditioned inside an oven for 30 minutes to get a uniform temperature all over the specimen. A contactless image analysis technique using a CANON camera with a frame rate of 50 images per second allows the strain measurement by following
(A)

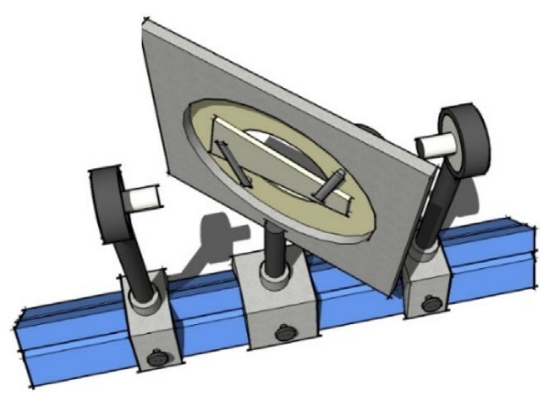

(B)

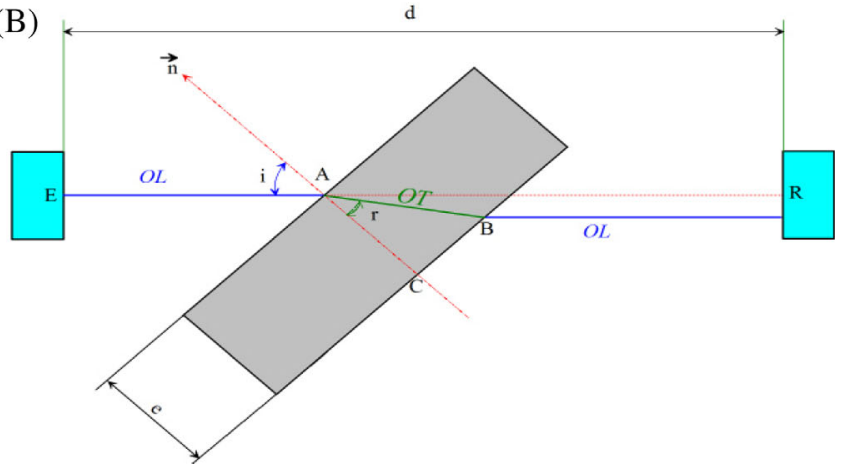

FI G U RE 3 A, Sample holder used for ultrasonic characterization allowing control of angle of incidence (i) as well as direction of propagation of the transverse waves. B, Principle of ultrasonic method: determination of speed of transverse waves [Color figure can be viewed at wileyonlinelibrary.com] 


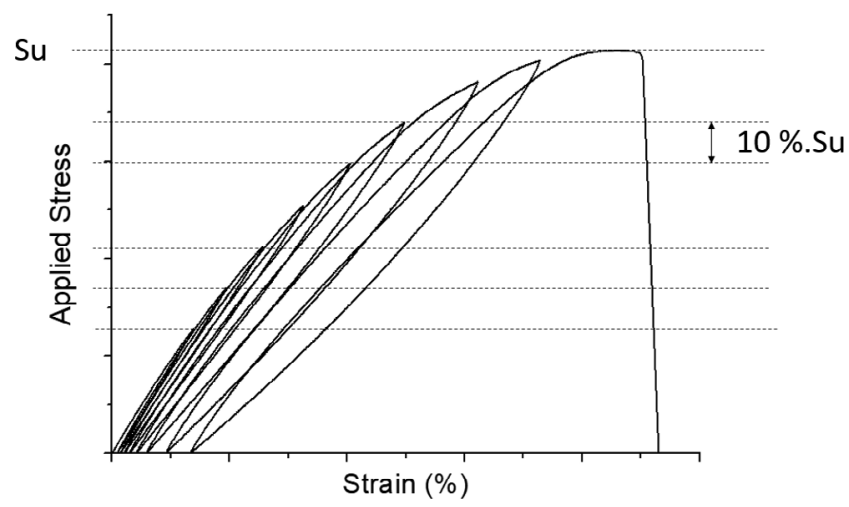

FI G U RE 4 Loading-unloading tests procedure

the relative displacement of two marked points drawn on the surface of the specimen before testing. The video-obtained by the camera are treated with the software ImajeJ and the strain measurement is then synchronized with the data machine.

\subsection{2 | Damage analysis in monotonic loading}

To study the evolution of the macroscopic damage and apparent plasticity at the quasi-static regime, loadingunloading tests at different increasing maximum applied stresses are performed at a crosshead speed of $2 \mathrm{~mm} / \mathrm{min}$ and at room temperature. For each test, the sample is submitted to a total of eight to ten loading-unloading cycles at a gradual increasing stress gap of about $10 \%$ of the ultimate tensile stress $\left(\sigma_{\mathrm{u}}\right)$, as shown in Figure 4. The residual strain at a zero stress gives an evaluation of the residual macroscopic apparent plastic strain. Young's modulus is evaluated by the slope of the curve at the beginning of each cycle.

\subsection{3 | Fatigue tests}

Fatigue tests are performed at different applied maximum stresses $\left(\sigma_{\max }\right)$ on the MTS 830 servo-hydraulic fatigue machine. A sinusoidal signal is applied under stress-controlled mode, the constant amplitude and the fixed loading ratio. To prevent the specimen from buckling, the chosen stress ratio $\mathrm{R}$ is 0,1 . The main study frequency is $10 \mathrm{~Hz}$; however, a second frequency of $1 \mathrm{~Hz}$ is used in order to study the effect of velocity and selfheating on the fatigue performance. The mechanical behavior during fatigue of the three types of samples tested $\left(0^{\circ}, 90^{\circ}\right.$, and $\left.45^{\circ}\right)$ is investigated by means of stiffness reduction, evolution of apparent plastic strain and

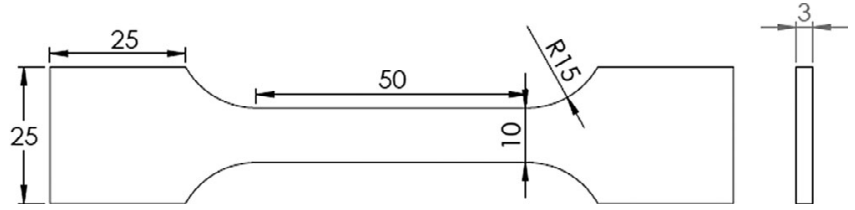

FI G URE 5 Specimen geometry

self-heating. The temperature of the specimen is followed using a contactless infrared camera. The strain measurement during fatigue is done using the displacement data given by the machine coupled with a correction factor.

\section{4 | Specimen for mechanical testing}

To overcome the problems related to the machining process, tensile specimens are obtained by a water jet cutting technique from injected plates. Specimens are extracted from the center of the plates and a globally uniform microstructure. To study anisotropy, specimens were cut along three directions: $0^{\circ}, 90^{\circ}$, and at $45^{\circ}$ regarding the injection direction. Figure 5 shows the dumb-bell specimen geometry allowing uniform stress repartition along the working area.

\section{3 | RESULTS AND DISCUSSIONS}

\section{1 | Microstructure analysis}

The microstructure obtained from the injection molding process has been largely studied in the literature ${ }^{[13,36-38]}$ In fact, the shear flow is maximum at the mold surface, making the fibers well oriented in the flow direction. However, at the core, the shear flow is negligible which makes them perpendicular to the flow direction. Arif et $\mathrm{al}^{[13]}$ used the X-ray microcomputed tomography $(\mu \mathrm{CT})$ technique on short fiber-reinforced polyamide and distinguished four types of microstructures. First, the skin layer was oriented with random fibers. Then the fibers in the shell layer were mainly oriented in the injection direction. After that, a shell-core transition layer was oriented with random fibers. Finally, core layer with fibers oriented perpendicularly to the injection direction. The SEM observations confirm the presence of this microstructure distribution for our material. Figure 6 is a reconstitution of multiple images taken with SEM along the thickness with a 200 times magnification. The typical skin-shell-core microstructure of the injected material clearly appears. 


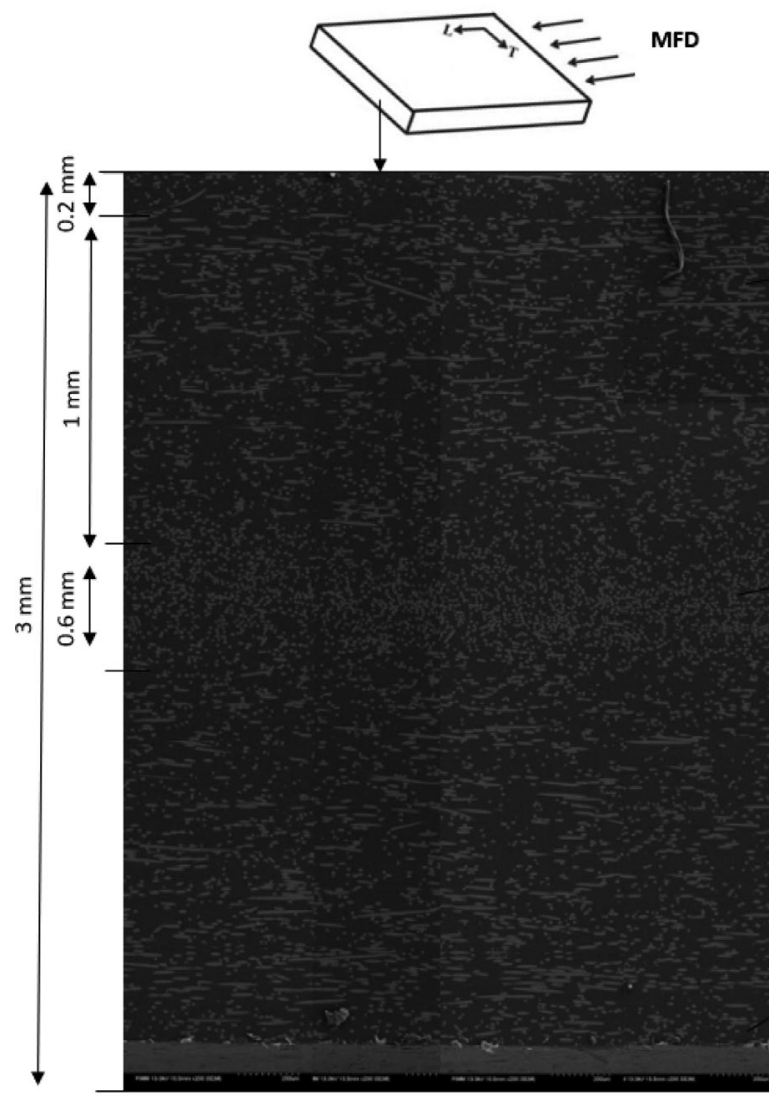

It can be noted that the shell layers represent about $66 \%$ of the sample thickness.

The original ultrasonic method described in Section 2.2.2 is used to analyze the spatial distribution of the microstructure of the plate. Sixteen rectangular samples are cut from the rectangular injected plate (Figure 7). Figure 7A represents the locations of the samples in the plate and Figure 7B depicts the corresponding polar diagrams of the shear wave velocity. The latter clearly reveals a strongly orientated microstructure in the injection direction. Despite the simple geometry of the plate small variations can be distinguished from one location to another. Indeed, the main orientation of fibers is not always found in the mold flow direction especially at some edges of the studied area. For example, samples 5,14 , and 16 show a main orientation direction at $30^{\circ}$ from the injection direction. Another observation is that the velocity of the shear ultrasonic wave drops by more than $70 \%$ when passing from the main fiber orientation to the transverse direction, this indicate a highanisotropic behavior of used material. Following these results, we have decided to extract the mechanical test specimens from the central zone of the plate in which the microstructure is homogeneous and well oriented in the mold flow direction. In the following, a $0^{\circ}$ specimen means that it has been cut in the mold flow direction.
F I G U RE 6 Skin: A,

shell. B, core. C, microstructure, inducted by injection molding

\section{2 | Thermomechanical analysis}

To study the effect of the temperature, DMTA tests are performed using dual cantilever at a strain of $0.01 \%$ and frequencies of 1 and $10 \mathrm{~Hz}$. Figure 8 illustrates the evolution of the storage and loss modulus for the two frequencies vs temperature.

In this figure, three different zones can be identified corresponding to the glassy state, glass transition zone, and rubbery state. It is demonstrated also that raising the frequency leads to increasing $\mathrm{E}^{\prime}$ and $\mathrm{E}^{\prime \prime}$ without changing the transition temperature. Indeed, it must be noted that evolution $\mathrm{E}^{\prime \prime}$ shows three peaks corresponding to the three transitions $\mathrm{T}_{\beta}\left(\right.$ at $\left.-30^{\circ} \mathrm{C}\right), \mathrm{T}_{\alpha}$ (at $10^{\circ} \mathrm{C}$ ) and $\mathrm{T}_{\alpha c}\left(\right.$ at $\left.70^{\circ} \mathrm{C}\right) \cdot \mathrm{T}_{\beta}$ corresponds to the movement of short molecular segments. For an amorphous polymer, $\mathrm{T}_{\beta}$ corresponds to the ductile-brittle transition temperature. $T_{\alpha}$, which is generally related to the glass transition temperature, is not affected by the presence of fibers. For pure polypropylene (PP) $\mathrm{T}_{\alpha}$ is around $10^{\circ} \mathrm{C} . \mathrm{T}_{\alpha c}$, which corresponds to the mobility of chains near the surface of crystallites, [24] goes up from $50^{\circ} \mathrm{C}$ for pure PP to nearly $70^{\circ} \mathrm{C}$ when introducing fibers. This is probably due to the stiffening of the chain segments in this intermediate zone between the amorphous phase and the crystalline phase and 
FI G URE 7 Position in

plate of 16 pieces used for

ultrasonic measurements and corresponding polar diagrams [Color figure can be viewed at wileyonlinelibrary.com]
(A)

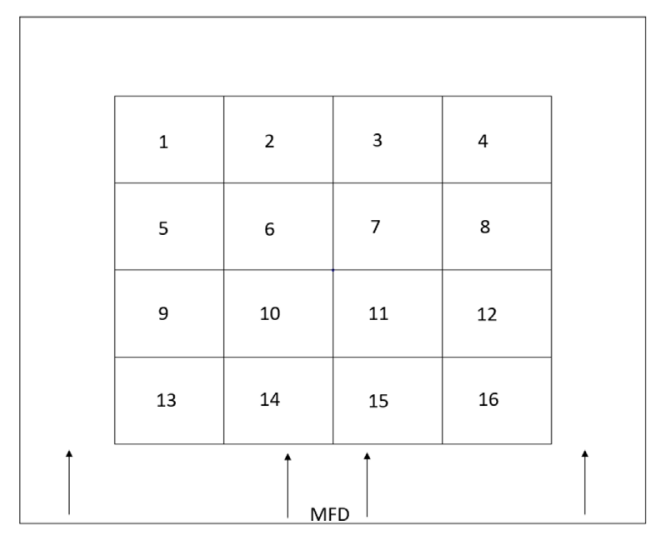

(B)

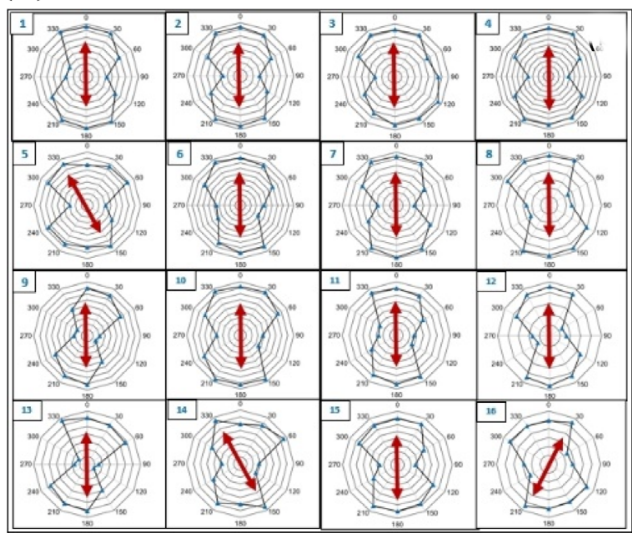

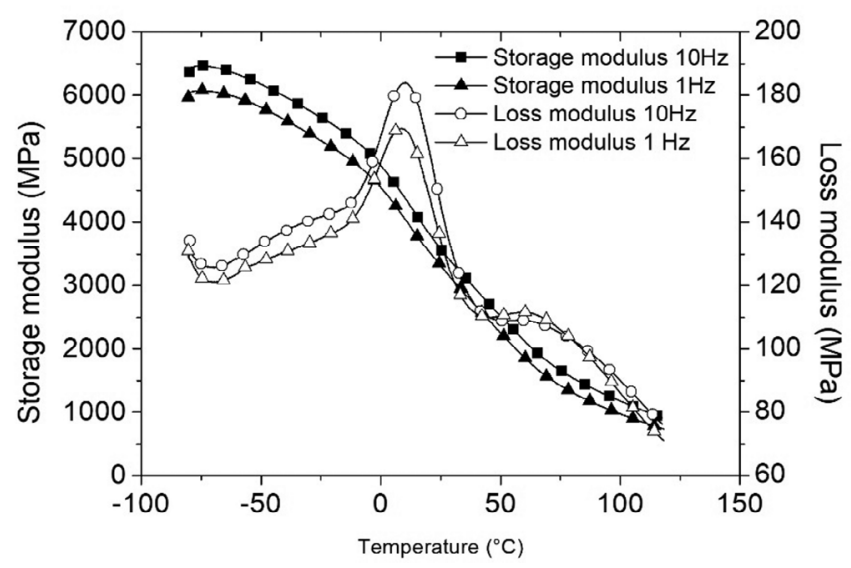

F I G U RE 8 Storage modulus during dual cantilever DMA test at different frequencies

optionally the transcrystallization at the fiber matrix interface.

\subsection{1 | Effect of fiber orientation on tensile properties}

The tensile properties of PPGF40 composites are described in Figure 9. Five specimens are tested for all fiber directions, the main mechanical characteristics of the material are reported in Table 1 by the means of their averages and deviations. The strong anisotropy induced by the injection molding process of the material is well illustrated. Indeed, specimens loaded in the longitudinal direction show higher mechanical properties than those in transversal (almost 100\% increase in Young's modulus and ultimate stress) and $45^{\circ}$ direction. However, transverse and $45^{\circ}$ specimens show more ductile properties characterized by higher elongation at fracture.

It is interesting to note that for the three sample orientations the stress-strain curves exhibit a nonlinear

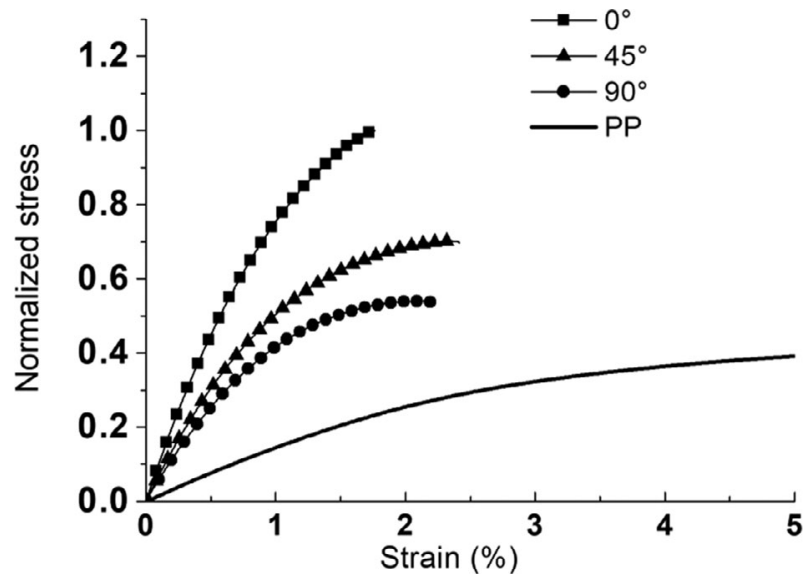

F I G U RE 9 Tensile normalized stress-strain curves of PPGF40 at room temperature for $0^{\circ}, 45^{\circ}, 90^{\circ}$ directions and $\mathrm{PP}$ at a crosshead speed of $2 \mathrm{~mm} / \mathrm{min}$ corresponding to strain rate of $0.0004 \mathrm{~s}^{-1}$. PP, polypropylene

behavior caused by plasticity and damage. Note that an elastic behavior rises when the fibers are misoriented vs tensile direction. Indeed, in this case, matrix and fiber matrix interfaces are more solicitated than in the case of longitudinal-loading, for which a minimum nonlinear behavior is observed.

\subsection{2 | Temperature effect on tensile properties}

Tensile behavior of PPGF40 highly depends on temperature due to the relatively low-glass transition temperature of the PP (about $5^{\circ} \mathrm{C}$, see Figure 8 ). ${ }^{[23]}$ Figure 10 illustrates the effect of high $\left(+85^{\circ} \mathrm{C}\right)$ and low temperature $\left(-30^{\circ} \mathrm{C}\right)$ on the tensile properties; it shows that at $85^{\circ} \mathrm{C}$, the material is still highly anisotropic, but Young's modulus and the maximum stress drop for more than 50\% in comparison with the results at room temperature. 
However, ductility is improved by more than $350 \%$ even for the longitudinal direction. At $-30^{\circ} \mathrm{C}$ there is an improvement of the maximum stress, but the change of Young's modulus remains neglectable. This effect is probably due to the $\beta$ transition of the matrix in a glassy state, related to the molecular mobility of short chain segments.

\subsection{3 | Strain rate effect on tensile properties}

The materials under investigation show a strong strain rate-dependent behavior. ${ }^{[16,25,39-42]}$ The study made by Fitoussi et $\mathrm{al}^{[41]}$ demonstrated that mechanical characteristics, in terms of damage and plastic strain threshold, ultimate properties, were highly sensitive to the strain rate. As the strain rate rose, Young's modulus would increase by $50 \%$. The "visco-damage" effect that they introduced produce a delay of the first damage

T A B LE 1 Summary of mechanical properties of tested configurations

\begin{tabular}{|lcccl}
\hline \multirow{2}{*}{$0^{\circ}$} & & $\mathbf{E}(\mathbf{M P a})$ & $\boldsymbol{\sigma}_{\max }(\mathbf{M P a})$ & $\boldsymbol{\varepsilon}_{\max }(\mathbf{m m} / \mathbf{m m})$ \\
& Avrg & 7883.3 & 84.85 & 0.02 \\
\hline $45^{\circ}$ & devi & 277.8 & 1.58 & 0.001 \\
& Avrg & 5090 & 55.89 & 0.03 \\
\hline $90^{\circ}$ & devi & 432 & 1.14 & 0.002 \\
& Avrg & 4466.7 & 44.01 & 0.025 \\
\hline \multirow{2}{*}{ Pure PP } & Avrg & 1045 & 31 & 0.002 \\
& devi & 75 & 2 & 0.39 \\
\hline
\end{tabular}

Abbreviation: PP, polypropylene. phenomenon, a slower damage rate at high-strain rate and a delay in the plastic strain threshold.

Even for a strain rate less than $1 \mathrm{~s}^{-1}$, a slight improvement of Young's modulus and the maximum stress may be observed. Indeed, Figure 11 shows an improvement of $20 \%$ at strain rate of $0.25 \mathrm{~s}^{-1}$ for the three microstructures in comparison with quasi-static loading performed at $4.10^{-4} \mathrm{~s}^{-1}$. At a higher strain rate, the improvement should be much more important. ${ }^{[16]}$ In fact, the viscoelastic behavior of the matrix impacts the composite response. $^{[21,26,27,41]}$

\subsection{4 | Macroscopic damage and apparent plasticity evolution during loading-unloading tests}

Figure 12 illustrates both the loading-unloading response and the monotonic stress-strain curves for the three configurations $0^{\circ}, 45^{\circ}$, and $90^{\circ}$. This figure demonstrates that there is no significant gap between the monotonic and the cyclic envelopes for all sample orientations. This confirms that there is no significant change in the behavior of PPGF40 by the loading-unloading test compared to tensile loading.

Damage and residual strain (apparent plastic strain) evolution during loading-unloading quasi-static tests is analyzed in Figure 13. Three specimens are tested for each configuration. For the three microstructures, the plasticity threshold is lower than the damage threshold. Therefore, the presence of two deformation stages can be noticed: the first one involving matrix an elasticity and the second one coupling damage to plasticity. Maximum damage and plasticity are observed for the transverse direction followed by the $45^{\circ}$ direction and then the longitudinal direction, which exhibits the lower levels of damage and plasticity.
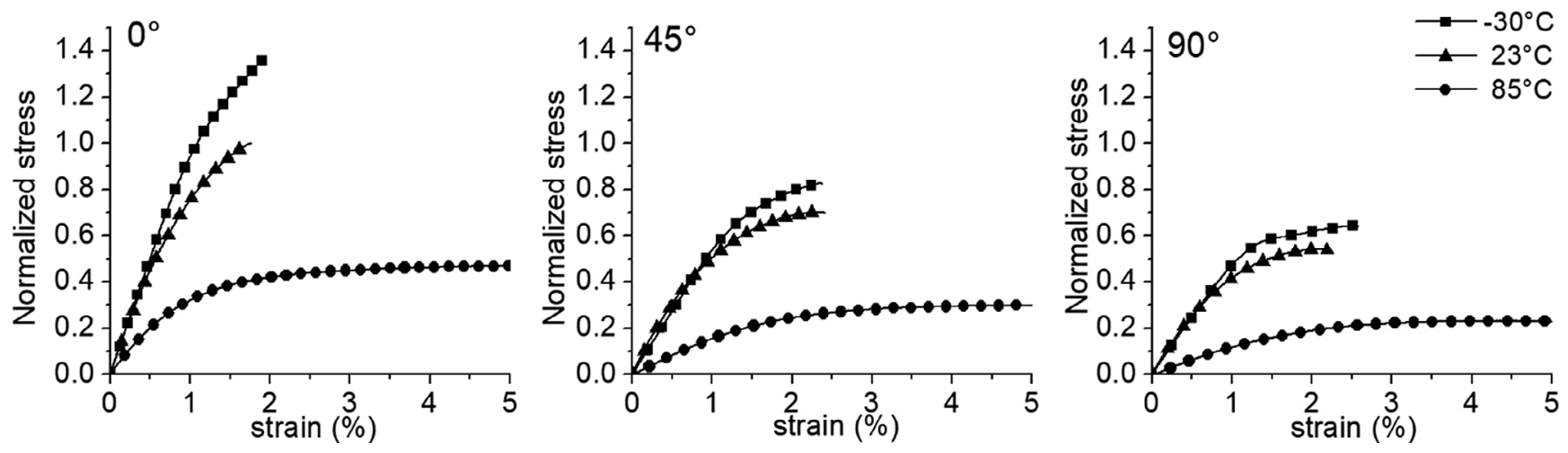

F I G U RE 10 Tensile normalized stress-strain curves of PPGF40 at $23^{\circ} \mathrm{C},-30^{\circ} \mathrm{C}$, and $85^{\circ} \mathrm{C}$ for $0^{\circ}, 45^{\circ}$, and $90^{\circ}$ directions at crosshead speed of $2 \mathrm{~mm} /\left(\min 0.0004 \mathrm{~s}^{-1}\right)$ 

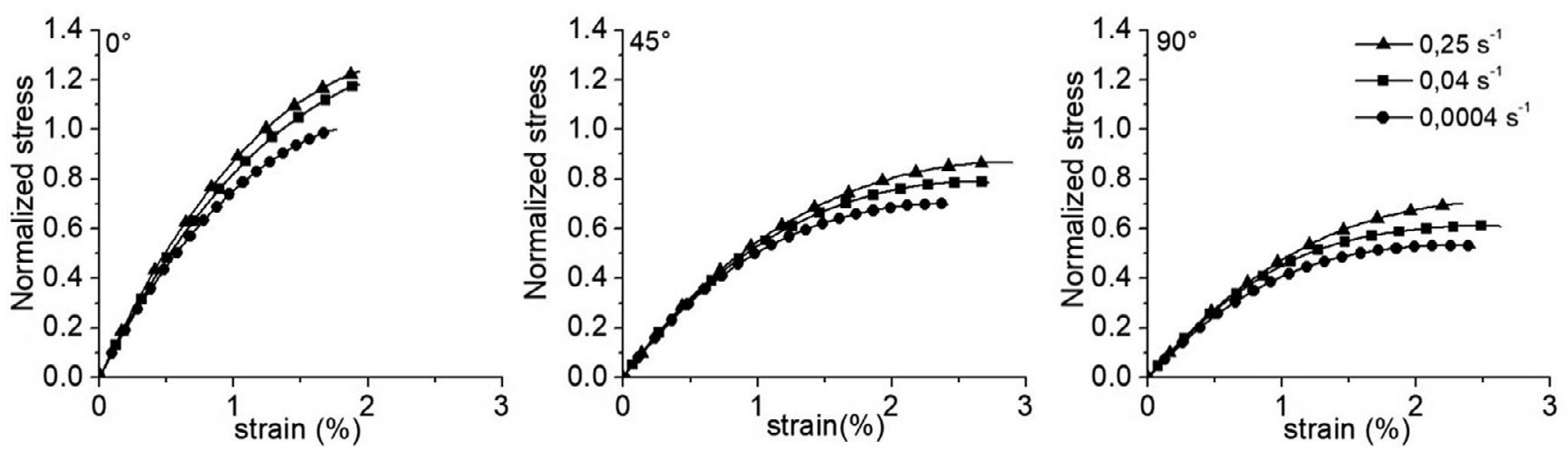

F I G U RE 11 Tensile normalized stress-strain curves of PPGF 40 at different strain rates and room temperature
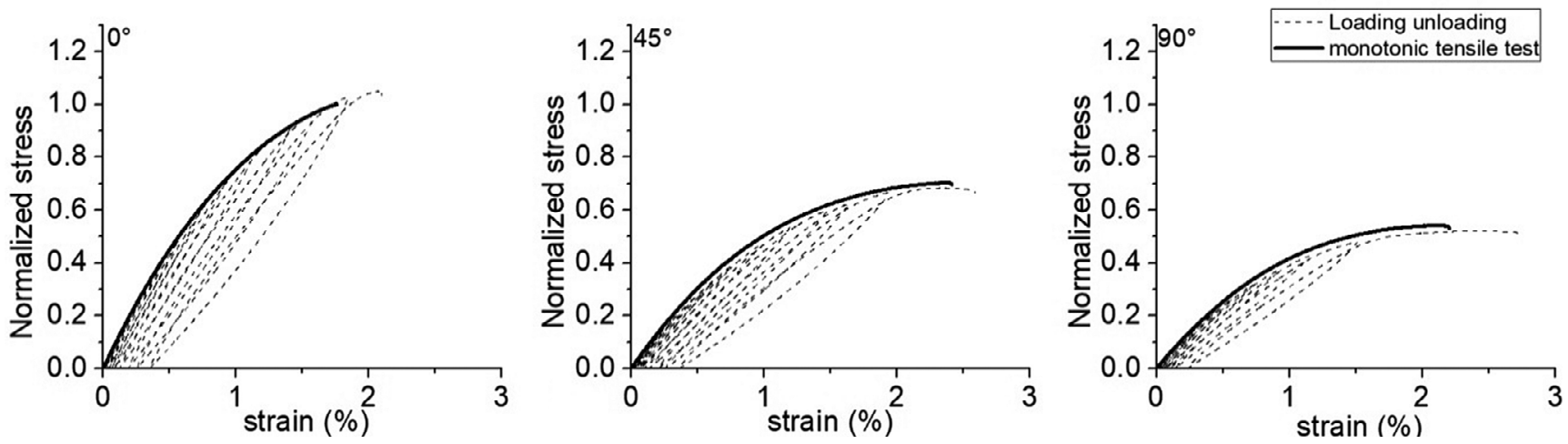

FI G U RE 12 Loading-unloading and monotonic normalized stress-strain curves for $0^{\circ}, 45^{\circ}$, and $90^{\circ}$

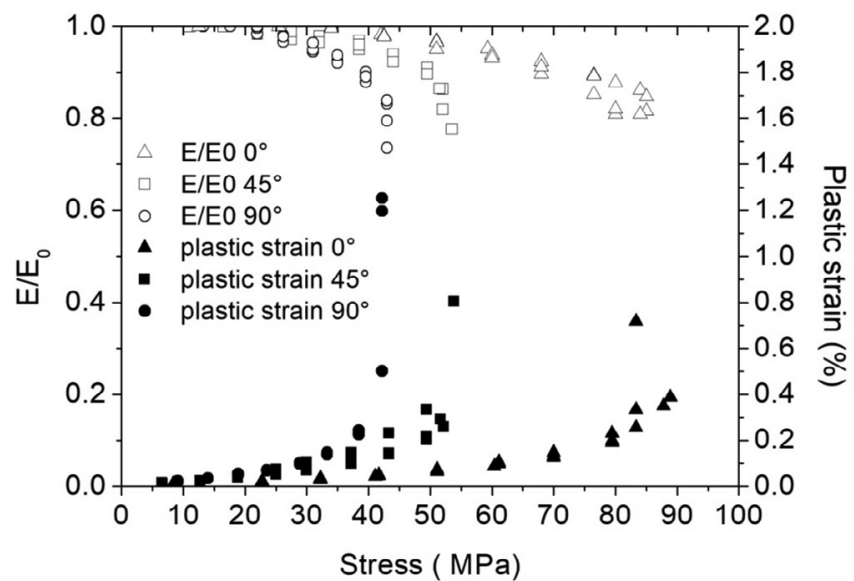

F I G U R E 13 Stiffness loss and plasticity evolution during loading-unloading tests

From Figure 13, the value of the plastic stain reached at the threshold of damage: $\varepsilon_{P}^{\text {th }}$.can be extracted This value should be directly read in Figure 14 for each orientation. Therefore, the difference between the total plastic strain, $\varepsilon_{P}$ and $\varepsilon_{P}^{\text {th }}$, represents the increment of plastic strain during the second stage involving both damage

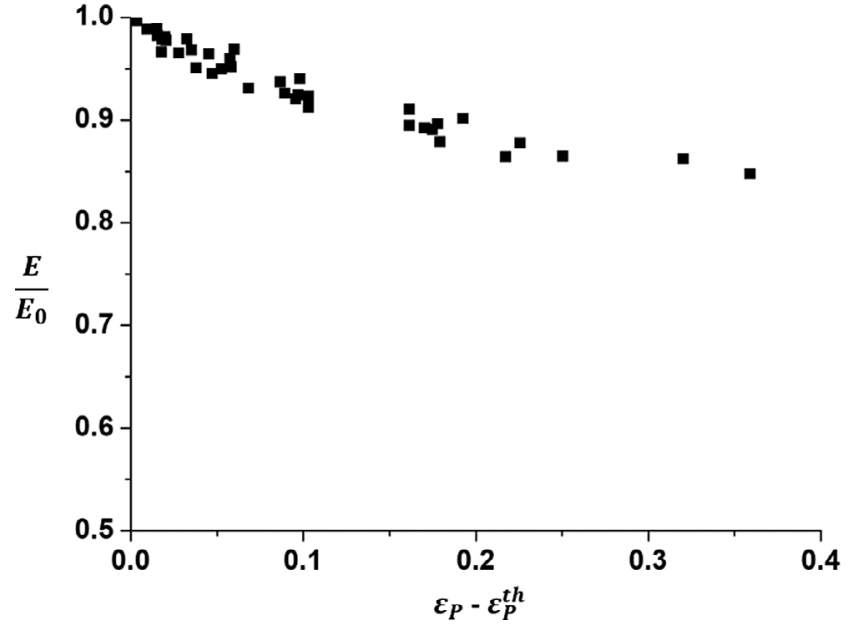

F I G U R E 14 Stiffness loss as a function of plastic strain at damage threshold

and plasticity. Thus, the coupling effect of damage and plasticity should be emphasized by plotting the evolution of the loss of stiffness, $\frac{E}{E_{0}}$ vs $\varepsilon_{P}-\varepsilon_{P}^{\text {th }}$. Figure 15 shows that this evolution follows a unique curve for all the orientations. This means that there is an intrinsic relation 

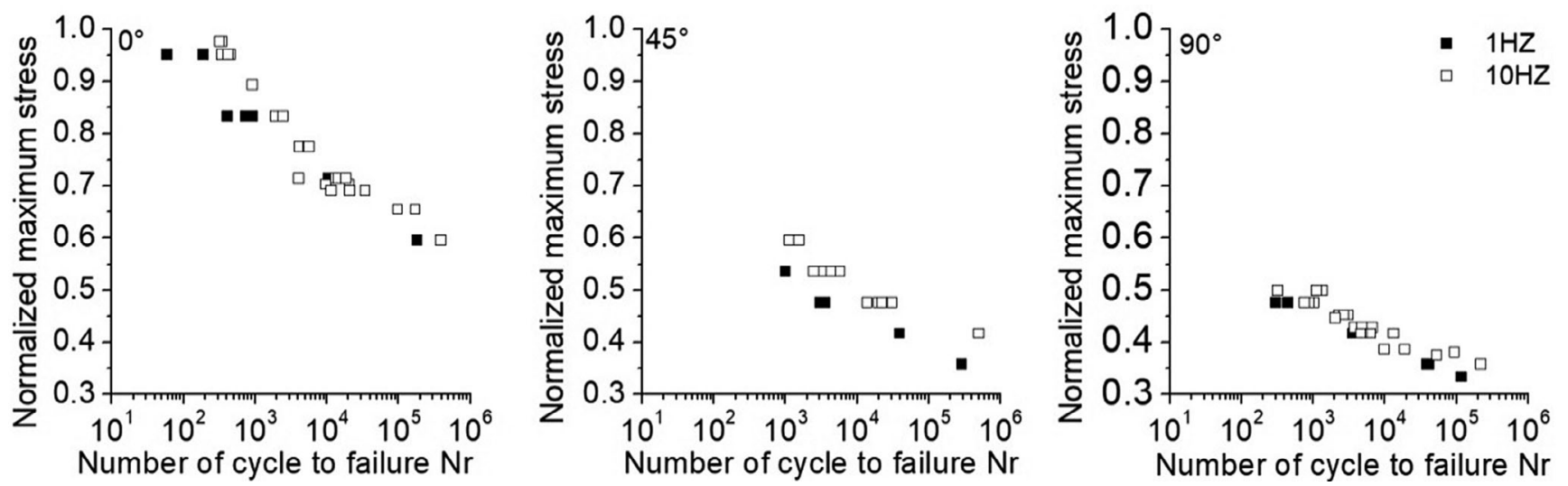

F I G U RE 15 S-N curves at frequencies of 10 and $1 \mathrm{~Hz}$

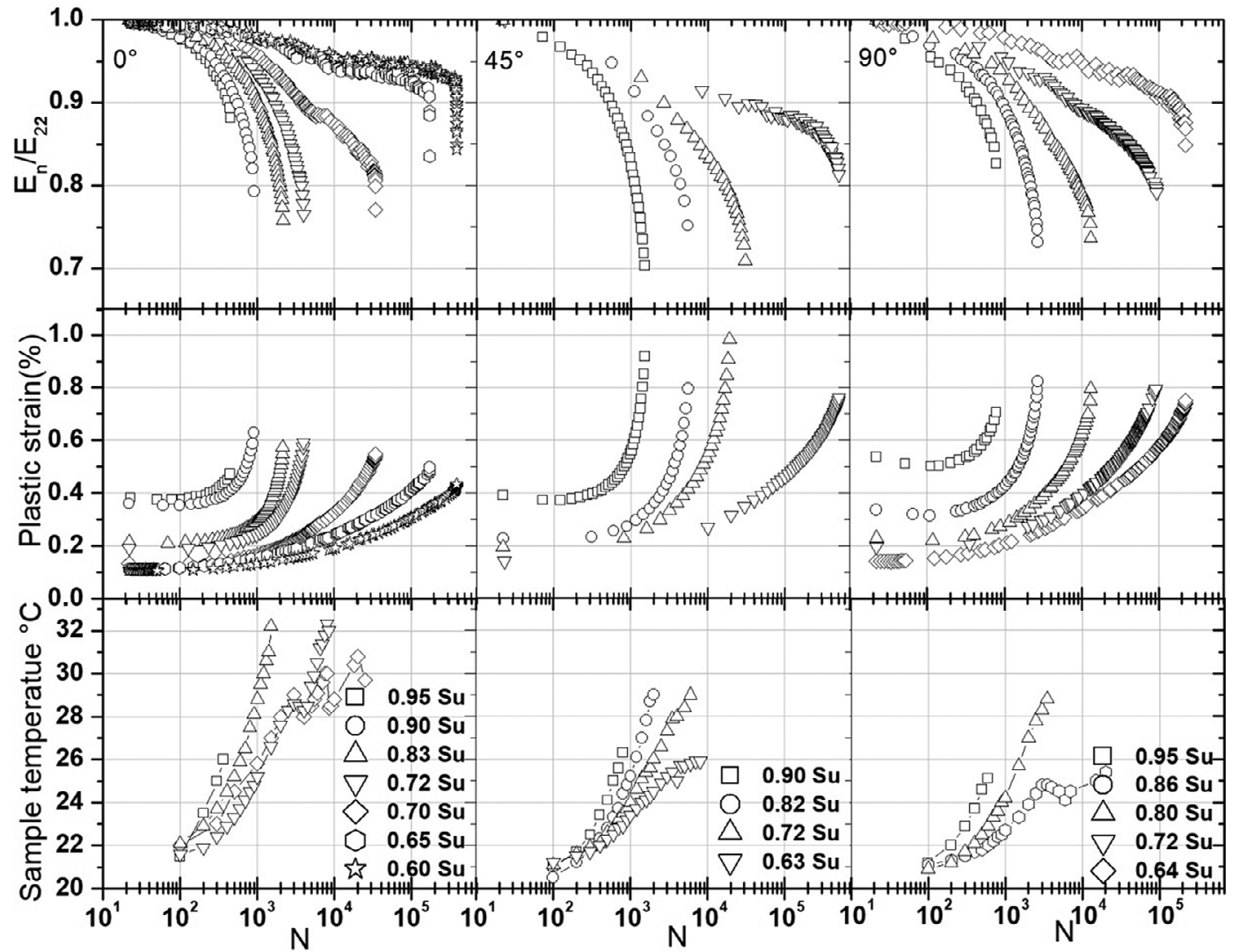

F I G U RE 16 Evolution of normalized dynamical modulus, maximum plastic strain and temperature during fatigue

between the macroscopic loss of stiffness and the increment of plastic strain during the second stage involving both damage and plasticity. As a consequence, it can be concluded that for a given microstructure, knowing the stiffness loss for applied loading leads directly to the corresponding plastic strain, independently of the orientation of fibers. This result should be useful for component design.

\section{3 | Fatigue behavior}

\subsection{1 | Effects of loading amplitudes and frequency}

Figure 15 represents the $10 \mathrm{~Hz}$ and $1 \mathrm{~Hz} \mathrm{S-N}$ curves for the three directions. In concordance with tensile results, the longitudinal direction shows the fatigue strength 

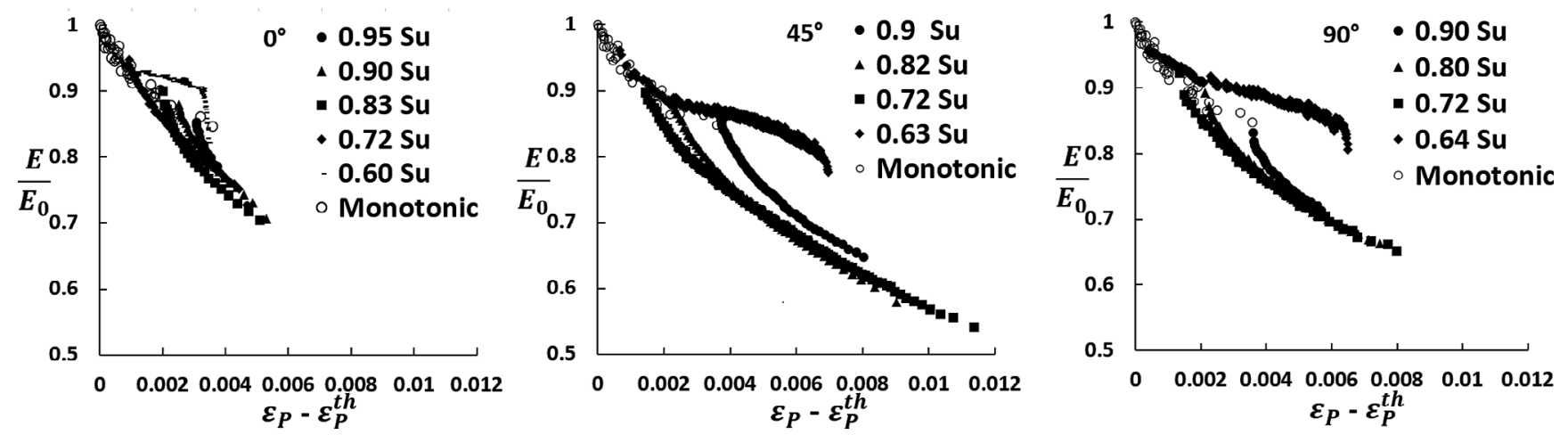

F I G U R E 17 Stiffness loss as function of plastic strain subtracted by plastic strain at the damage threshold during fatigue loading

twice higher than the transverse direction. It is interesting to note that the fatigue life is slightly improved when increasing the frequency from 1 to $10 \mathrm{~Hz}$. The average strain rate undergone during a $10 \mathrm{~Hz}$ fatigue test is about $0.25 \mathrm{~s}^{-1}$. As it was depicted in Figure 8, at this rate, the material exhibits higher mechanical properties due to matrix visco-plasticity and visco-damage. Therefore, the plasticity and coupled damage plasticity stages emphasized in Figure 10 may be influenced in terms of thresholds (delayed) and kinetics (lower). This can explain the improvement of the fatigue strength. Moreover, Figure 16 illustrates the evolution of the stiffness loss, apparent plastic strain and the temperature of the specimens during fatigue. These results show that the longitudinal direction presents the maximum temperature evolution with self-heating of $10^{\circ} \mathrm{C}$. This temperature is reached for medium amplitudes. Indeed, lower and higher amplitudes exhibit lower self-heating. It can also be noted that a variation in the temperature from $22^{\circ} \mathrm{C}$ to $32^{\circ} \mathrm{C}$ due to self-heating corresponds to a variation of the storage modulus from 3725 to $3275 \mathrm{MPa}$ (a variation of 12\%), as represented in Figure 8. Therefore, the strain rate effect shown in Figure 11 together with possible higher deformation possibility due to self-heating lead to a slight improvement of the fatigue strength at $10 \mathrm{~Hz}$.

\subsection{2 | Macroscopic damage and plasticity evolution}

Figure 16 illustrates the evolutions of the normalized dynamic modulus, the maximum plastic strain, and temperature for the three studied orientations. Considering continuum damage mechanics, the loss of dynamic stiffness can be used as a damage indicator during fatigue. For amplitudes higher than $0.85 \mathrm{~S}_{\mathrm{u}}$ (where $\mathrm{S}_{\mathrm{u}}$ is the ultimate stress), the dynamic modulus decreases rapidly in a linear logarithmic regime until fracture of the specimen. For amplitudes between $0.85 \mathrm{~S}_{\mathrm{u}}$ and $0.60 \mathrm{~S}_{\mathrm{u}}$, the dynamic

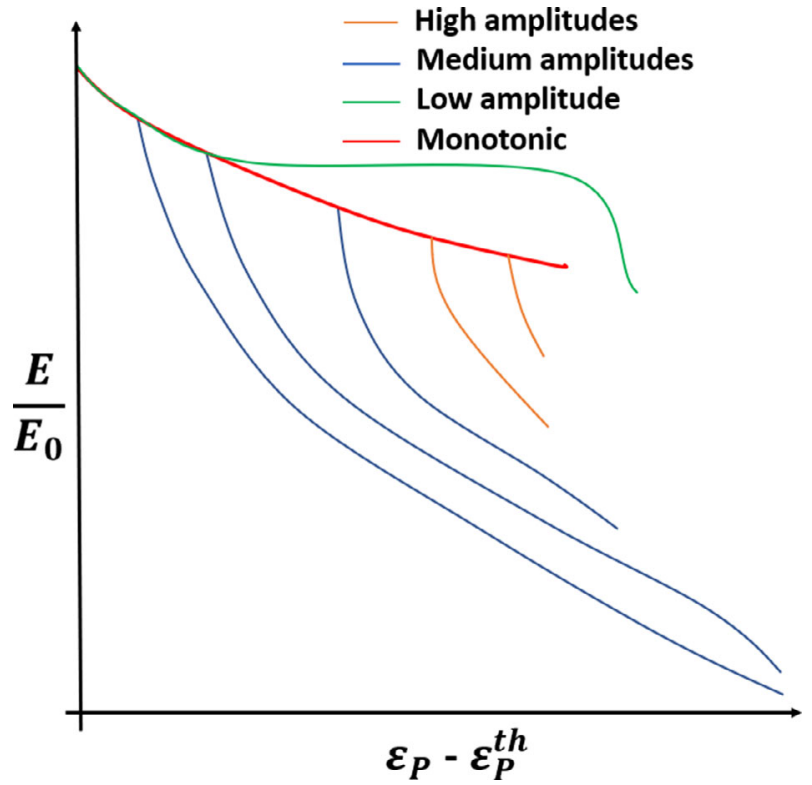

F I G U R E 18 Schematic of damage plasticity coupling as function of fatigue amplitudes [Color figure can be viewed at wileyonlinelibrary.com]

modulus exhibits three decreasing regimes: a rapid one during the first 1000 cycles, followed by a gradual one, and finally a drastic decrease just before fracture. It is noted that for amplitude below $0.6 \mathrm{~S}_{\mathrm{u}}$, the specimen exhibit a higher fatigue life up to $10^{6}$ cycles. It is interesting to notice that medium amplitudes exhibit the greatest values of stiffness loss and plastic strain. For high amplitudes, damage mechanisms and failure occur rapidly so that stiffness loss, plastic strain, and self-heating cannot evolve until reaching the maximum values.

As it is analyzed in Section 3.2.4 for quasi-static loading, the coupling effect of damage and plasticity during fatigue should be analyzed. First, it is obvious from Figure 16 that after a first increment due to the first cycle, plastic strain remains stable while stiffness decreases. Thus, contrary to quasi-static loading where the first 


\section{Tensile}
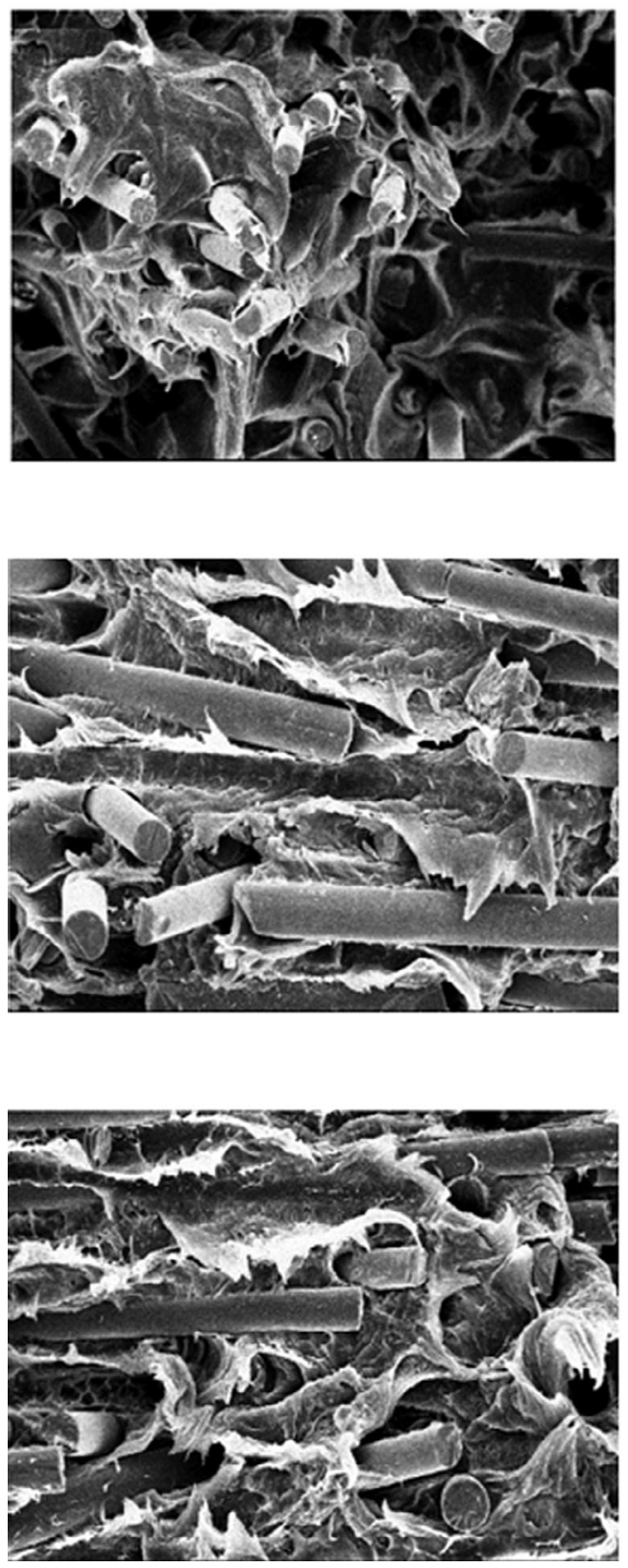

$90^{\circ}$

FI G URE 19 Fracture faces for tensile and fatigue tests

stage is described by plasticity without damage, for fatigue loading, the first stage corresponds only to the damage phenomenon. However, generally after 1000 cycles, plastic strain and damage increase together rapidly during a second stage.

As in Figure 14, Figure 17 depicts the coupling effect of damage and plasticity during the second stage of the fatigue tests. Some general comments can be made:

- For the three orientations, it can be noticed that the stiffness reduction vs plastic strain curves in fatigue start like the monotonic curve, but they do not show

\section{Fatigue}
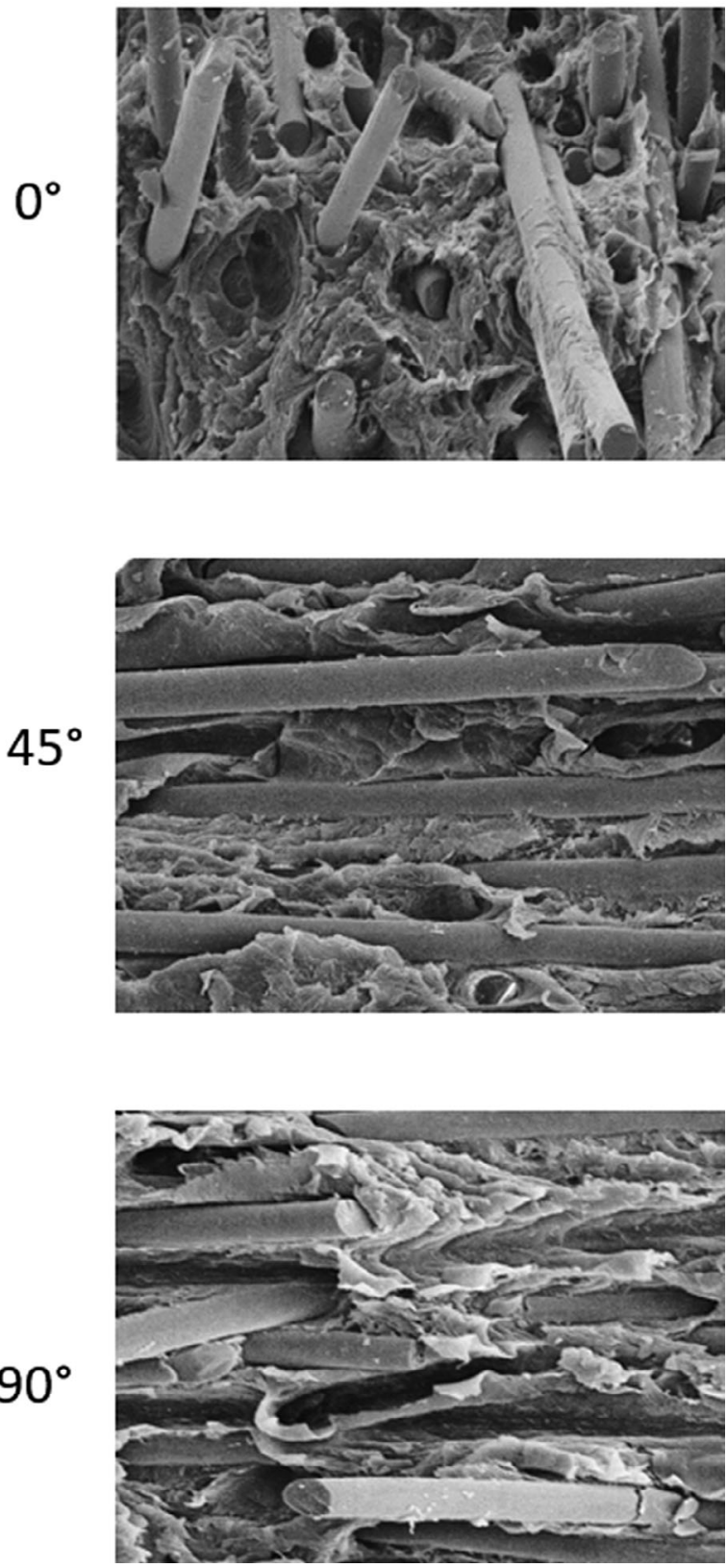

the same kinetics. In fact, the maximum damage and plastic strain reached under fatigue are considerably greater than those reached during monotonic tests (up to $\times 2.5$ for damage and $\times 2$ for plastic strain). This is probably due to the local plastic strain cumulated around the fiber during cyclic loading, which behaves as a barrier that prevents fiber matrix interface microcracks from branching off into the matrix, so that damage and plasticity can diffuse more largely through the material.

- However, this effect is limited when the fibers are oriented in the loading direction $\left(0^{\circ}\right)$. Indeed, in this case, 
matrix plasticity and fiber matrix interface damage are reduced.

- Two stages are observed: The first stage is characterized by a strong damage kinetic, which means that to a given plastic strain increment corresponds a sharp loss of stiffness. The latter effect increases when increasing the amplitude. Then, damage kinetics decreases progressively to level off around an average kinetic, which appears to be quite independent of the orientation and applied stress amplitude. However, for very high amplitude, this stabilized second stage may disappear because of early failure.

- The higher levels of damage and plastic strain are generally obtained for the lowest applied maximum stress. Indeed, when applying high-stress amplitude, the plastic strain barrier around the fibers may be crossed more easily due to higher local stress concentration. Consequently, the redistribution of the local stress and strain may be limited, and microcrack coalescence may occur earlier leading to precocious failure.

- For very low amplitudes, the coupling curves during fatigue begin to follow the monotonic one; then damage seems to saturate. This leads to a plasticity dominant stage where the coupling curve remains almost flat. Finally, a third-drastic damage stage occurs leading to the fracture of the specimen.

Figure 18 resumes the different stages of the damage plasticity evolution for different applied stress amplitudes.

\section{$3.4 \quad$ Fracture surfaces}

Figure 19 illustrates the SEM fracture surfaces for tensile and fatigue tests. For the three direction and for both monotonic and fatigue loading, the creation of cavities or microvoids can be observed around the fiber matrix interface, indicating local plasticity before debonding. A lot of studies have been interested in the creation of these cavities, we can, for example, cite those of Achour et al ${ }^{[43]}$ who reported a damage scenario starting with the creation of cavities and microcracks at the glass fiber ends. The second stage of the damage is characterized by the propagation of microcracks around the fiber; the coalescence of microcracks lead to a fast crack growth leading to failure.

For fatigue loading, plastic deformation can be also observed in the form of striations located around the fibers. This confirms the above interpretation of a plastic deformation barrier located around the fibers, which allows avoiding microcracks propagation through the matrix and leading to larger damage and deformation.
The SEM images reveal higher ductility for tensile tests. In fact, under monotonic loading, the matrix just around the fibers does not accumulate plastic deformation while under fatigue, local cyclic loading can result in highplastic strain concentration around the fibers. This high ductility observed for monotonic loading leads to more fiber pullout in comparison with the fatigue loading. The same remark was advanced in the works of Noda et al. ${ }^{[32]}$

\section{4 | CONCLUDING REMARKS}

The overall mechanical properties of PPGF40 are studied based on of monotonic, loading-unloading, and fatigue tensile tests. The effects of the temperature and the strain rate are illustrated. Fatigue tests are performed at two different frequencies and a slight improvement of the fatigue strength is observed at $10 \mathrm{~Hz}$. The dynamic modulus, the plastic strain and the self-heating evolution are used to analyze the evolution of the macroscopic properties of the composite during fatigue. Under fatigue loading, the fatigue stiffness reduction vs plastic strain increment curves always starts as the monotonic curve, but they do not show the same kinetics. Indeed, a sharp increase in damage and plasticity is emphasized for cyclic loading. A comparison between monotonic and fatigue fracture surfaces obtained by SEM observations provides an interpretation of the specific coupling effect between damage and plasticity occurring at the local scale during cyclic loading at its effect on the macroscopic properties of the composite.

\section{ACKNOWLEDGMENT}

This work is carried out as part of a Phd thesis ( CIFRE number 2016/1520) in collaboration between Arts et Metiers Institute of Technologie and Flex $\mathrm{N}$ gate Exteriors Europe.

\section{ORCID}

Mohamed A. Imaddahen (10) https://orcid.org/0000-00025681-0024

Mohammadali Shirinbayan (10) https://orcid.org/00000002-2757-8529

\section{REFERENCES}

[1] K. Friedrich, A. Almajid, Appl. Compos. Mater. 2012, 20, 107128

[2] S. Mortazavian, A. Fatemi, Int. J. Fatigue 2015, 70, 297.

[3] J. Karger-Kocsis Ed., Polypropylene Structure, blends and Composites, Springer, Budapest 2019. https://www.springer.com/ gp/book/9780412614200.

[4] B. Esmaeillou, J. Fitoussi, A. Lucas, A. Tcharkhtchi, Procedia Eng. 2011, 10, 2117.

[5] H. Nouri, F. Meraghni, P. Lory, Int. J. Fatigue 2009, 31, 934. 
[6] W. Van Paepegem, J. Degrieck, Int. J. Fatigue 2002, 24, 747.

[7] B. Li, Y. Chi, L. Xu, C. Li, Y. Shi, Constr. Build. Mater. 2018, 190,1236

[8] M. A. Laribi, S. Tamboura, J. Fitoussi, R. Tié Bi, A. Tcharkhtchi, H. Ben Dali, Compos. Part B Eng. 2018, 139, 155.

[9] H. Ayari, J. Fitoussi, A. Imaddahen, S. Tamboura, M. Shirinbayan, H. B. Dali, Appl. Compos. Mater. 2020, 27, 321. https://doi.org/10.1007/s10443-019-09793-3.

[10] S. Subramanian, K. L. Reifsnider, W. W. Stinchcomb, Int. J. Fatigue 1995, 17, 343.

[11] H. Mao, S. Mahadevan, Compos. Struct. 2002, 58, 405.

[12] P. Zuo, R. C. Benevides, M. A. Laribi, J. Fitoussi, M. Shirinbayan, F. Bakir, A. Tcharkhtchi, Compos. Part B Eng. 2018, 145, 173 .

[13] M. F. Arif, N. Saintier, F. Meraghni, J. Fitoussi, Y. Chemisky, G. Robert, Compos. Part B Eng. 2014, 61, 55.

[14] V. Bellenger, A. Tcharkhtchi, C. Ph, Int. J. Fatigue 2006, 28, 1348.

[15] N. Abbasnezhad, A. Khavandi, J. Fitoussi, H. Arabi, M. Shirinbayan, A. Tcharkhtchi, Int. J. Fatigue 2018, 109, 83.

[16] N. Jia, V. A. Kagan, Polym. Compos. 1998, 19, 408.

[17] M. Shirinbayan, J. Fitoussi, F. Meraghni, S. Farzaneh, B. Surowiec, A. Tcharkhtchi, Appl. Compos. Mater. 2019, 26, 1313.

[18] M. Shirinbayan, J. Fitoussi, F. Meraghni, B. Surowiec, M. Laribi, A. Tcharkhtchi, J. Reinf. Plast. Compos. 2016, 36, 271. https://journals.sagepub.com/doi/10.1177/0731684416682853.

[19] D. Notta-Cuvier, M. Nciri, F. Lauro, R. Delille, F. Chaari, F. Robache, G. Haugou, Y. Maalej, Mech. Mater. 2016, $100,186$.

[20] Z. Jendli, F. Meraghni, J. Fitoussi, D. Baptiste, Compos. Part Appl. Sci. Manuf. 2004, 35, 779.

[21] Nadia Achour Renault, Fodil MERAGHNI, Laurent Peltier, Joseph Fitoussi. Microstructural and experimental analysis of strain rate effect for short glass fiber reinforced polypropylene.Paper presented at: 20th Int. Conf. on Composite Materials (ICCM'20), 2015, Copenhague, Denmark. ffhal01218601.

[22] D.-H. Kim, S.-Y. Kang, H.-J. Kim, H.-S. Kim, Compos. Part B Eng. 2019, 166, 483.

[23] J. Viña, A. Argüielles, A. F. Canteli, Strain 2011, 47, 222.

[24] M. Eftekhari, A. Fatemi, Fatigue Fract. Eng. Mater. Struct. 2015, 38, 1395.

[25] M. Nciri, D. Notta-Cuvier, F. Lauro, F. Chaari, R. Delille, G. Haugou, Y. Maalej, B. Zouari, Polym. Compos. 2019, 40, 2850.
[26] J. Fitoussi, M. Bocquet, F. Meraghni, Compos. Part B Eng. 2013, 45, 1181.

[27] Z. Jendli, J. Fitoussi, F. Meraghni, D. Baptiste, Compos. Sci. Technol. 2005, 65, 387.

[28] J. J. HORST, J. L. SPOORMAKER, J. Mater. Sci. 1997, 32, 3641.

[29] J. J. Horst, J. L. Spoormaker, Polym. Eng. Sci. 1996, 36, 2718.

[30] N. Sato, T. Kurauchi, S. Sato, O. Kamigaito, J. Mater. Sci. 1991, 26,3891

[31] N. Sato, T. Kurauchi, S. Sato, O. Kamigaito, J. Mater. Sci. Lett. 1983, 2, 188.

[32] K. Noda, A. Takahara, T. Kajiyama, Polymer 2001, 42, 5803.

[33] J. Brunbauer, A. Mösenbacher, C. Guster, G. Pinter, J. Appl. Polym. Sci. 2014, 131, 1. https://onlinelibrary.wiley.com/doi/ abs/10.1002/app.40842.

[34] M. Shirinbayan, J. Fitoussi, N. Abbasnezhad, F. Meraghni, B. Surowiec, A. Tcharkhtchi, Compos. Part B Eng. 2017, 131, 8.

[35] H. Meftah, S. Tamboura, J. Fitoussi, H. BenDaly, A. Tcharkhtchi, Appl. Compos. Mater. 2018, 25, 507.

[36] P. A. Hessman, T. Riedel, F. Welschinger, K. Hornberger, T. Böhlke, Compos. Sci. Technol. 2019, 183, 107752.

[37] B. Mlekusch, Compos. Sci. Technol. 1999, 59, 547.

[38] J.-P. Trotignon, J. Verdu, J. Appl. Polym. Sci. 1987, 34, 19.

[39] M. B. F. M. J. Fitoussi, Compos. Part B 2013, 45, 1181.

[40] M. Todo, K. Takahashi, H. Kaush, Compos. Sci. Technol. 2000, 60, 763.

[41] J. Fitoussi, F. Meraghni, Z. Jendli, G. Hug, D. Baptiste, Compos. Sci. Technol. 2005, 65, 2174.

[42] I. S. E. S. A. Vashchenko, Metalurgika 2000, 39, 89.

[43] Achour N. Modélisation multi-échelle et analyse expérimentale du comportement de composites à matrice thermoplastique renforcés fibres de verre sous sollicitations dynamiques modérées. Paris, ENSAM; 2017 http://www. theses.fr/2017ENAM0062 